\title{
BMJ Open Metabolic risk factors for non- communicable diseases in Ethiopia: a systematic review and meta-analysis
}

\author{
Tilahun Tewabe Alamnia (D) , ${ }^{1,2}$ Wubshet Tesfaye (D) , ${ }^{3}$ Solomon Abrha, ${ }^{4,5}$ \\ Matthew Kelly (i) ${ }^{1}$
}

To cite: Alamnia TT, Tesfaye W, Abrha S, et al. Metabolic risk factors for non-communicable diseases in Ethiopia: a systematic review and meta-analysis. BMJ Open 2021;11:e049565. doi:10.1136/ bmjopen-2021-049565

- Prepublication history and additional supplemental material for this paper are available online. To view these files, please visit the journal online (http://dx.doi.org/10.1136/ bmjopen-2021-049565).

Received 26 January 2021 Accepted 22 October 2021

Check for updates

(C) Author(s) (or their employer(s)) 2021. Re-use permitted under CC BY-NC. No commercial re-use. See rights and permissions. Published by BMJ.

${ }^{1}$ Department of Global Health, National Centre for Epidemiology \& Population Health, Australian National University, Canberra, Australian Capital Territory, Australia

${ }^{2}$ College of Medical and Health Sciences, Bahir Dar University, Bahir Dar, Ethiopia

${ }^{3}$ Health Research Institute, University of Canberra, Canberra, Australian Capital Territory, Australia

${ }^{4}$ Faculty of Health, University of Canberra, Canberra, Australian Capital Territory, Australia

${ }^{5}$ College of Medicine and Health Sciences, Mekelle University, Mekelle, Ethiopia

Correspondence to

Tilahun Tewabe Alamnia;

Tilahun.Alamnia@anu.edu.au

\section{ABSTRACT}

Objectives Non-communicable diseases (NCDs) are causing a new and yetsignificant health challenge in lowincome countries. In Ethiopia, although $39 \%$ of deaths are NCD related, the health system remains underprepared, highlighting the clear need for evidence on risk factor distributions to inform resource planning and the health response. Therefore, this review investigates prevalence distributions and sex and age variations of metabolic risk factors among Ethiopian adults.

Research design and methods This systematic review used the Preferred Reporting Items for Systematic Reviews and Meta-Analyses guidelines. Studies published until 6 January 2021 were searched from PubMed, Scopus, ProQuest and Web of Science databases, reference lists of selected studies and grey literature. Studies reporting prevalence of metabolic risk factors: overweight/obesity, hypertension, impaired glucose homoeostasis and metabolic syndrome among Ethiopian adults were eligible for this systematic review and meta-analysis. Two authors independently extracted data and used the Joanna Briggs Institute tool for quality appraisal. The random effects model was used to conduct meta-analysis using Stata V.16. Subgroup analyses examined prevalence differences by region, study year, sample size and settings.

Results From 6087 records, 74 studies including 104382 participants were included. Most showed high prevalence of metabolic risk factors. Meta-analysis revealed pooled prevalence of metabolic risk factors from $12 \%$ to $24 \%$ with the highest prevalence observed for overweight/obesity (23.9\%, 95\% Cl 19.9\% to $28.0 \%$ ) and hypertension (21.1\%, $95 \% \mathrm{Cl} 18.7 \%$ to $23.5 \%$ ), followed by metabolic syndrome $(14.7 \%, 95 \% \mathrm{Cl} 9.8 \%$ to $19.6 \%)$ and impaired glucose tolerance $(12.4 \%, 95 \% \mathrm{Cl} 8.7 \%$ to $16.1 \%)$. The prevalence of overweight/obesity was higher in women. All metabolic risk factors were higher among people aged above 45 years. Conclusions A signficant proportion of Ethiopian adults have at least one metabolic risk factor for NCDs. Despite heterogeneity of studies limiting the certainty of evidence, the result suggests the need for coordinated effort among policymakers, healthcare providers, non-governmental stakeholders and the community to implement appropriate preventive measures to reduce these factors.

\section{INTRODUCTION}

Non-communicable diseases (NCDs) are the leading causes of death worldwide, but they disproportionately affect people living

\section{Strengths and limitations of this study}

This is the first systematic review and meta-analysis combining studies with similar characteristics in the context of metabolic risk factors for noncommunicable diseases (NCDs) in Ethiopia.

- The study provided comprehensive evidence of prevalence of metabolic risk factors of NCDs among adults in Ethiopia which can be easily used for planning intervention to decrease NCD incidence in the population.

- The certainty of the evidence of this review is limited by heterogeneity of the included studies, which hampered the ability to calculate combined pooled prevalence of multiple risk factors.

-We did not find studies conducted in some regions of the country like Afar, Benishangul-Gumuz, Gambella regions, so the prevalence estimates might not reflect the realities in these regions.

in low-income and middle-income countries (LMICs). ${ }^{1}$ In 2017 , more than $73 \%$ of global deaths (41 million) were attributed to NCDs. ${ }^{1}$ Of these, more than $80 \%$ were due to cardiovascular diseases, cancer, chronic respiratory diseases and diabetes mellitus (DM).${ }^{12}$ About $75 \%$ (28 million) of all NCDs-related deaths across the globe and $82 \%$ (16 million) of the premature deaths occurred in LMICs. In the WHO African Region, the burden of NCDs is gradually increasing and is anticipated to overtake the burden of mortality and morbidity from communicable diseases by the year 2030. ${ }^{3}$ The same holds true in Ethiopia where, NCDs were estimated to cause around $43 \%$ of deaths in $2019 .{ }^{4}$

Most NCDs-related deaths are attributed to major risk factors which can be broadly categorised into behavioural (tobacco smoking, alcohol drinking, sedentary lifestyle and high dietary salt intakes) and metabolic (overweight/obesity, high fasting plasma glucose, high blood pressure (BP) and high level of blood triglycerides) factors. ${ }^{3}$ The continual increase in the prevalence of metabolic risk 
factors, often reinforced by behavioural factors, has been associated with a direct increase in prevalence of NCDs, especially among adults between the ages of 30 and 70 years. $^{2}$

According to the 2017 Global Burden of Disease Study, metabolic risk factors contributed to a substantial proportion (26\%) of the total disability-adjusted life-years (DALYs). High BP, high fasting plasma glucose, high body mass index (BMI) and high cholesterol are responsible for $9 \%, 7 \%, 6 \%$ and $4 \%$ of global DALYs, respectively. ${ }^{5}$ Besides, the 2019 estimates on DM prevalence revealed that 463 million people $(9 \%)$ have diabetes and this number is projected to rise to 700 million $(11 \%)$ by $2045 .{ }^{6}$ LMICs have been disproportionately affected by these problems and the burden of these diseases is likely to increase in LMICs in Africa. ${ }^{5}$

The 2030 United Nations agenda for sustainable development has set a target to reduce one-third of premature mortality form NCDs. ${ }^{7}$ In line with this, WHO has set out a milestone plan to prevent and control premature mortality from cardiovascular diseases, cancer, DM or chronic respiratory diseases by $25 \%$ in 2025 , which can be achieved by reducing the burden of metabolic risk factors and its contributing behavioural and lifestyle factors among adults using affordable and accessible intervention strategies. ${ }^{8}$ However, to implement these interventions and achieve the intended goals, up-to-date, representative and comprehensive evidence is always needed. The Ethiopian government prepared national guidelines for NCDs prevention and management in line with the global target in $2016,{ }^{9}$ but there is a lack of evidence on the successes of ongoing implementation and programme evaluations of the proposed strategies. There is also a lack of comprehensive data on the prevalence of the immediate predictors of NCDs to implement focused interventions and make policy decisions.

There has been no systematic review of the prevalence of metabolic risk factors in Ethiopia. Although some studies have reviewed the prevalence of hypertension, their results are inconclusive due to lack of methodological rigour such as including participants with varying characteristics and/or were performed more than 5 years ago. There is no available comprehensive evidence for the remaining three risk factors: impaired glucose tolerance, overweight/obesity and metabolic syndrome. Furthermore, previous individual studies have shown a conflicting association between metabolic risk factors and participants' characteristics, such as sex and age. For instance, some showed that hypertension was higher in women and older adults, while others in men and in younger people. To this end, we aimed to conduct this systematic review and meta-analysis to (1) determine the pooled prevalence of metabolic risk factors of NCDs in Ethiopian adults; (2) examine differences in the distribution of metabolic risk factors across regions, year of study, sample sizes and study settings; and (3) test the associations of metabolic risk factors with the sex and age of participants.
We hypothesised that (1) metabolic risk factors for NCDs are higher among adults due to the life course cumulative increase in risk caused by behavioural factors in this age group, (2) there would be variations in the prevalence of these risk factors across regions and settings of the study and (3) the prevalence of metabolic risk factors would vary by demographic characteristics. Estimating the prevalence of metabolic risk factors for NCDs in Ethiopia is essential to identify the priority areas for policy action, inform practices through various intersectoral collaborations and decide future research directions. The result of this study can be used by central and regional governments, respective health authorities, nongovernmental stakeholders and healthcare providers to design and deliver health effective interventions to reduce the burden of NCDs in Ethiopia.

\section{METHODS}

\section{Study design}

This systematic review and meta-analysis was conducted and reported in accordance with the Preferred Reporting Items for Systemic Reviews and Meta-analyses (PRISMA). ${ }^{10}$ It includes key research questions, information sources, eligibility criteria, study selection, data extraction, risk of bias assessment, and data analysis, results and discussion. The process of screening and selection of studies, the results of the analysis and narrative descriptions were supported with figures and tables for reporting this study.

\section{Patient and public involvement}

No patients or public were involved in the design, conduct, interpretation or dissemination of the results of this study.

\section{Research questions}

The key research questions that initiated this review were: (1) What is the level of metabolic risk factors of NCDs among adults in Ethiopia? (2) Is there a difference in the distribution of metabolic risk factors across regions in Ethiopia, by time period, settings and sample sizes? (3) What is the age and sex differences in the distribution of metabolic risk factors of NCDs?

\section{Eligibility criteria}

Based on these research questions, we identified Population, Exposure and Outcome (PEO) for eligibility criteria. Since the review was based on prevalence studies, we did not define controls. The population in this study was any adult living in Ethiopia. The adult was defined as person between the ages of 18-64. However, in some studies, adults were referred over the age of 15 . To maximise the generalisability of our study findings, we used both definitions for this systematic review and meta-analysis. Exposures were variables that might contribute to high prevalence of metabolic risk factors, including sociodemographic and economic variables but in this study, we only used the age and sex 
of participants to compare differences in metabolic risk factors. The outcome variables for this study were metabolic risk factors, such as overweight/obesity, hypertension, impaired glucose homoeostasis and metabolic syndrome. Thus, this review included studies conducted in Ethiopia and published in English language which reported a prevalence of at least one of the metabolic risk factors (overweight/obesity, impaired glucose tolerance, hypertension and metabolic syndrome) in adults with a cross-sectional or cohort designs and published until 6 January 2021. Whereas papers with only abstracts, qualitative studies, articles with a case control design, and research involving participants from vulnerable groups (children and pregnant women) or having preexisting chronic medical conditions were excluded as these factors were considered potential confounders of the outcomes of interest. Studies conducted in other languages were not considered due to translation issues. However, there was no published article found other than English including in Amharic (Ethiopian official language). Eligible studies were independently screened and evaluated by two authors following the predefined data fields.

\section{Information sources}

First, we developed search strategies, identified key terms and selected databases. These were developed in collaboration with all authors. We also searched PubMed Medical Subject Headings for additional keywords to expand our search scope to include all available evidence. Before we performed the main search, the search method was piloted in the selected databases. We did not use any restrictions, including language, to maximise our search results. Overall our key terms include: "metabolic risk factors", "cardiometabolic risk factors", "metabolic syndrome", "dyslipidemia*”, "dyslipidaemia*”, "hyperlipidemia*", "hyperlipidaemia*”, "high cholesterol", "hypercholesterolemia", "hypercholesterolaemia", "triglycerides", "hypertriglyceridemia", "hypertriglyceridaemia", "overnutrition", "malnutrition", "overweight", "obesity", "obese", "blood glucose", "impaired glucose tolerance", "glucose intolerance", "high blood glucose", "hyperglycemia", "high fasting plasma glucose", "insulin resistance", "diabetes", "diabetes mellitus", "blood pressure", "high blood pressure", "hypertension", "systolic blood pressure", "diastolic blood pressure" and "Ethiopia”. Then two reviewers (TTA and WT) independently searched PubMed, Embase via Scopus, ProQuest and Web of Science databases for relevant studies from their inception to 6 January 2021. The reference lists of the included articles in this systematic review and meta-analysis and grey literatures were reviewed and hand searched to identify additional relevant articles. The search results were then exported to Endnote V.X9 reference manager software and to Covidence ${ }^{11}$ for removing duplicates, screening and study selection.

\section{PubMed search strategy}

( ( ("metabolic risk factors" OR "cardiometabolic risk factors" OR "metabolic syndrome" OR dyslipidemia* OR dyslipidaemia* OR Hyperlipidemia* OR hyperlipidaemia* OR "high blood cholesterol" OR hypercholesterolemia OR hypercholesterolaemia OR triglycerides OR hypertriglyceridemia OR hypertriglyceridaemia) OR (overnutrition OR malnutrition OR overweight OR obesity OR obese) OR ("blood glucose" OR "impaired glucose tolerance" OR "glucose intolerance" OR "high blood glucose" OR hyperglycemia OR "High fasting plasma glucose" OR "insulin resistance" OR diabetes OR "diabetes mellitus") OR ("blood pressure" OR "high blood pressure" OR hypertension OR "systolic blood pressure" OR "diastolic blood pressure")) AND (Ethiopia)). Full data search techniques and results are in online supplemental table 1 .

\section{Study selection}

To perform the screening, the records identified from the search results were exported to Endnote V.X9 reference manager software (Thomson Reuters, Philadelphia, Pennsylvania, USA) and then exported to Covidence virtual library. ${ }^{11}$ After duplicate records were removed, two reviewers (TTA and WT) independently screened the titles and abstracts of the retrieved articles guided by the predefined PEO and eligibility criteria. Following the selection of articles based on their titles and abstracts, a full-text review was conducted for the selected studies for further relevance and inclusion. Any disagreements during the screening process were resolved via discussion.

\section{Data collection process}

Two authors (TTA and WT) independently extracted key data from the included studies. The data extraction was conducted based on the modified version of the Joanna Briggs Institute (JBI) Meta-Analysis of Statistics and Review Instruments. ${ }^{12}$ Data extracted included study characteristics (authors name, type of metabolic risk factor studied, year of study, study area, study setting, study design, sample size, response rate, number of participants with the case), participant characteristics (age, gender, disease condition) and study outcome measures (prevalence of metabolic risk factors). Any disagreements encountered during information extraction were resolved via discussion.

\section{Risk of bias assessment}

Two reviewers (TTA and WT) independently assessed the quality of the included studies using JBI checklist ${ }^{13}$ developed for methodological quality assessment of prevalence studies that includes criteria of inclusion, description of subjects and the setting, reliability and validity of exposure measurement, criteria of measurement, identification and strategies to deal confounding factors, validity and reliability of outcomes measurement and statistical analysis used. The studies were scored on a scale of $0-1$ for eight items and studies with a total score of $<4,4-6$ 
and 7-8 were considered to have low, moderate and high methodological quality, respectively. Any disagreements in ratings the studies were resolved through discussion between the two reviewers.

\section{Outcome measures}

The main outcome of interest for this study was the prevalence of metabolic risk factors among adults in Ethiopia reported in the original articles in percentage (number of cases/total number of participants). We examined four metabolic risk factors: overweight/obesity, impaired glucose tolerance, hypertension and metabolic syndrome. The outcome variables were categorised based on the following definitions: overweight, defined as a BMI of $25-29.9 \mathrm{~kg} / \mathrm{m}^{2}$ and obesity as BMI $\left.\geq 30 \mathrm{~kg} / \mathrm{m}^{2}\right)^{214}$; impaired glucose tolerance (a fasting plasma glucose of 100 to $125 \mathrm{mg} / \mathrm{dL}$ or oral glucose tolerance test greater between 140 and $199 \mathrm{mg} / \mathrm{dL})^{15}$; high BP (a BP cut-off value of $\geq 140 / 90 \mathrm{~mm} \mathrm{Hg}$ on the average of BP measurements using a sphygmomanometer $)^{216}$ and metabolic syndrome (three or more of the following based on adult treatment panel III criteria: elevated triglyceride $(\geq 150 \mathrm{mg} /$ $\mathrm{dL})$, reduced high density lipoprotein $(<40 \mathrm{mg} / \mathrm{dL}$ for male and $<50$ for female), high BP $(\geq 130 / 85 \mathrm{~mm} \mathrm{Hg})$, high fasting plasma glucose $(\geq 110 \mathrm{mg} / \mathrm{dL})$ or increased waist circumference $(\geq 102 \mathrm{~cm}$ for men and $\geq 88 \mathrm{~cm}$ for women $)^{17}$ or waist circumference of $\geq 94 \mathrm{~cm}$ for men and $\geq 80 \mathrm{~cm}$ for women, and two of elevated triglycerides $(\geq 150 \mathrm{mg} / \mathrm{dL})$ or treatment for this lipid abnormality; reduced high density lipoprotein cholesterol $(<40 \mathrm{mg} / \mathrm{dL}$ in men and $<50 \mathrm{mg} / \mathrm{dL}$ in women) or treatment for lipid abnormality; high BP $(\geq 130 / 85 \mathrm{~mm} \mathrm{Hg})$ or treatment for hypertension; impaired fasting serum glucose $(\geq 100 \mathrm{mg}$ / $\mathrm{dL}$ ) or previously diagnosed with type 2 diabetes based on international diabetes federation criteria). ${ }^{18}$ Additional outcomes include the variation of the metabolic risk factors by age and gender of participants.

\section{Data analysis}

Relevant information on the study area, study setting, study design, study sample, study response rate and study outcome were extracted using Microsoft Excel and exported to Stata V.16 (StataCorp) for the meta-analysis. The characteristics of included studies were summarised and presented using tables and figures (forest plots). The random effects restricted maximum likelihood meta-analysis model was used to pool studies with homogeneous outcomes, given it is more robust in terms of variance estimation in small sample studies. ${ }^{19}$ Forest plots along with the respective 95\% CIs were generated for individual studies and the pooled data to show graphic summaries of the analyses. Heterogeneity across studies was assessed using the $\mathrm{I}^{2}$ index, values greater than $75 \%$ indicated substantial heterogeneity. ${ }^{20}$ The Z-statistic was used for testing associations with $\alpha \leq 0.05$ as cut-off to determine statistical significance level. Then we identified studies that reported statistically significant associations between sex or age of participants and metabolic risk factors to extract ORs, CIs and $p$ values. This is because, often, studies provided OR, CIs and $p$ values only when significant associations were observed. The log of ORs was then used to determine the pooled association between each metabolic risk factor and the sex and age of the participants.

\section{Publication bias}

The presence of significant publication bias was assessed using funnel plot and the Begg and Egger's test. The symmetry of the funnel plot was visually inspected to assess the normal distribution studies around the centre of funnel plot. ${ }^{21}$ Then, the Begg's funnel plot and Egger's test for small-study effects ${ }^{22}$ were used to objectively assess the risk of bias across studies.

\section{Subgroup analysis}

Subgroup analyses were performed to examine the difference in prevalence of metabolic risk factors across the following variations:

1. Study regions: this was based on the nine ethnolinguistically based regions of the country (Afar, Amhara, Benishangul-Gumuz, Gambela, Harari, Oromia, Somali, 'Southern Nations, Nationalities and Peoples Region' and Tigray) and two city administrations of the country (Addis Ababa city administration and Dire Dawa city council).

2. Years of the study: we divided year of study in to three categories studies: conducted before 2000, studies conducted between 2000 and 2010, and studies performed between 2011 and 2020. This classification was chosen by the authors to show differences in the prevalence of metabolic risk factors in adults across ten-year age ranges, which we thought would allow sufficient variation for comparisons to be made.

3. Study settings: community based versus institution based. This classification was intended to compare prevalence of metabolic risk factors among adults selected from institutions (schools, banks and health facilities) and from the general community where there would be a difference in participant characteristics. For instance, the former is more likely to represent educated and health literate adults whereas the latter likely comprises less wealthy and uneducated community members.

4. Sample size: less than 400 vs 400 and above. The sample size classification was based on the authors' objective to compare the prevalence of metabolic risk factors between studies with small sample size and large sample size.

The results of subgroup analysis were presented in tables with prevalence's, 95\% CIs and $\mathrm{I}^{2}$ statistics test results. The statistical significance for subgroup analysis results was also determined at a p-value $<0.05$.

\section{Trim-and-fill analysis}

Trim-and-fill analysis was used to assess the effect of remaining studies that might have been included and fill 
imputed studies based on bias corrected pooled prevalence's. Statistical significance was declared if the $p$ value is $<0.05$.

\section{Grading the certainty of evidence}

The certainty of the evidence was assessed using the Grading of Recommendations Assessment, Development and Evaluation (GRADE) approach. This approach identifies systematic reviews and meta-analysis as a magnifying glass thorough which analysis of evidence is viewed and applied. Evidence from observational studies generally start with initial low certainty. The certainty of evidence of the outcomes (metabolic risks) was downrated for risk of bias, inconsistency (heterogeneity), indirectness of evidence, imprecision and publication bias. ${ }^{23}$

\section{RESULTS}

\section{Study selection}

A total of 6087 records were identified from database and hand searching of reference lists of the included studies and grey literatures. After removal of duplicates $(\mathrm{n}=2900)$, ineligible articles $(\mathrm{n}=3045)$ were removed articles based on their titles and abstracts. One hundred and forty-two publications were then eligible for fulltext retrieval and screening. Of these, 14 articles were excluded due to their participants including children and adolescents, 27 studies were excluded due to participants with confounding chronic diseases like diabetes, 2 articles were excluded due to previous similar reports, 18 studies were excluded because they did not explicitly record, measure, or report the outcomes, and 7 articles were excluded due to their study design (case control). No unpublished relevant study was found, and no records were excluded due to a low-quality assessment. Finally, 74 articles involving a total of 104382 participants were included in this systematic review and meta-analysis. The study selection flow chart is shown in figure 1.

\section{Characteristics and risk of bias of included studies}

The characteristics of the included studies in this systematic review and meta-analysis are presented in online supplemental table 2. Out of 74 studies, 36 of them reported a point prevalence on hypertension, ${ }^{24-59} 14$ on impaired glucose tolerance, ${ }^{60-73} 18$ on overweight or obesity $^{74-89}$ and the remaining eight studies on metabolic syndrome. ${ }^{90-97}$ The studies were conducted in-Amhara $(\mathrm{n}=22),{ }^{25282932343841455053361-636570727578-8189}$ Oromia $(\mathrm{n}=9),{ }^{3536466269771879197}$ Southern Ethiopia $(\mathrm{n}=15),{ }^{31374044515557-59646774858694}$ Tigray $(\mathrm{n}=5),{ }^{26} 42437383$ Somali $(\mathrm{n}=1),{ }^{30}$ Addis Ababa city administration (n=14), ${ }^{24} 2733474854566066687788909293$ Dire Dawa city council $(\mathrm{n}=2)^{39} 96$ regions, and five ${ }^{49} 76828495$ of them were nationwide studies. All studies were cross-sectional in nature and most of them $(n=52)$ were communitybased studies. The sample sizes for the studies ranged from 68 to 10938 participants.

The risk of bias of included studies in this systematic review and meta-analysis were assessed and presented in
6087 records identified from databases, reference lists and grey literatures

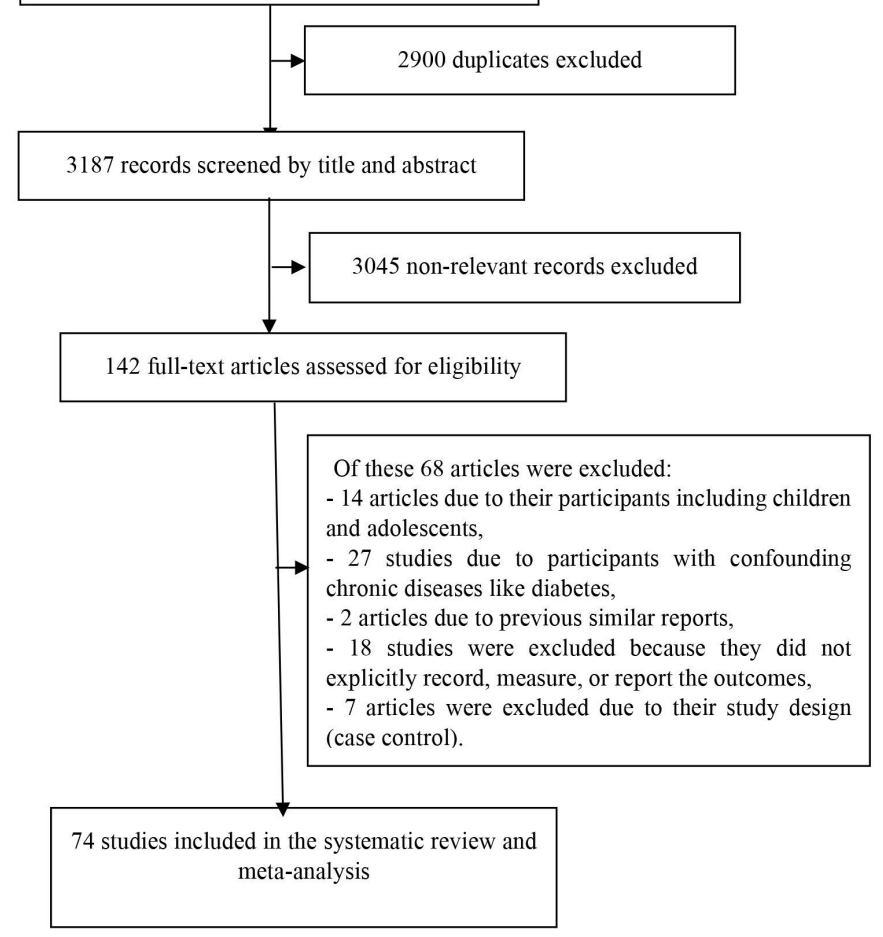

Figure 1 Study selection flow diagram.

online supplemental table 2 . The overall risk of bias in the included studies was considered to be low: $66(89 \%)$ had low risk of bias, while the remaining eight studies $(11 \%)$ had moderate level of risk of bias. None of the included studies had high risk of bias. Overall, the GRADE assessment of quality of evidence provided a low certainty of evidence to support prevalence estimates and associations with the age and sex participants (online supplemental table 3).

\section{Prevalence of hypertension}

A total of 36 studies involving 47204 adult participants reported on prevalence of hypertension were included in this analysis. Of these studies, most were conducted in Amhara region $(\mathrm{n}=11),{ }^{2526282932343841455053}$ Addis Ababa $(\mathrm{n}=7),{ }^{24273347485456}$ Southern Ethiopia $(\mathrm{n}=9)^{31374044515557-59}$ and there was one nationwide study. ${ }^{49}$ The prevalence of hypertension among individual studies ranged between $3 \%$ in Amhara region ${ }^{53}$ and $34.7 \%$ in Addis Ababa. ${ }^{33}$ Meta-analysis result showed the pooled prevalence of hypertension was $21.1 \%$ (95\% CI $18.7 \%$ to $23.4 \%$, certainty of evidence: moderate), with substantial heterogeneity among the included studies $\left(\mathrm{I}^{2}=97.6 \%\right.$; $\left.\mathrm{p} \leq 0.001\right)$ (figure 2 and online supplemental table 3).

\section{Prevalence of overweight/obesity}

With regard to overweight/obesity, 16 studies involving 28822 adult participants reported on prevalence of overweight/obesity were included in this analysis. ${ }^{74-89}$ Of these, six studies were from the Amhara region. ${ }^{75} 78-8189$ Looking at the distribution of overweight or obesity, the 


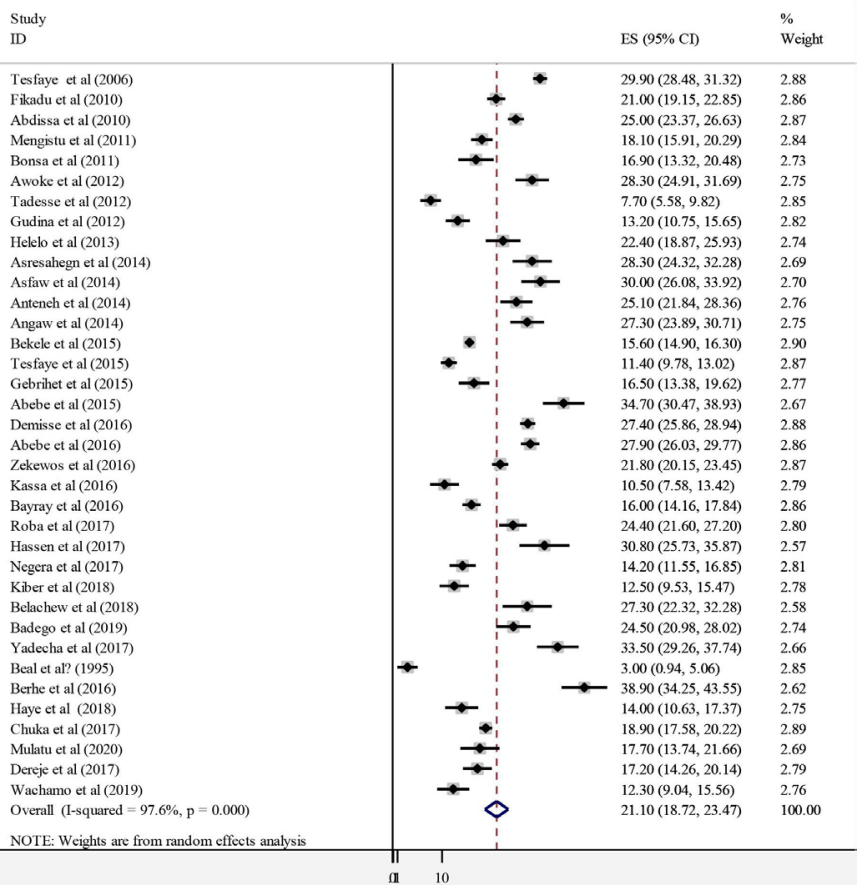

Figure 2 A forest plot of prevalence (\%) of hypertension among adults in Ethiopia. ES, effect size.

prevalence span from $9.7 \%$ from a nationwide study ${ }^{82}$ to $56.5 \%$ in a study conducted in Addis Ababa. ${ }^{87}$ The pooled prevalence of overweight/ obesity was estimated at 23.9\% (95\% CI $19.9 \%$ to $28.0 \%$, certainty of evidence: low). The presence of substantial heterogeneity in the included studies $\left(\mathrm{I}^{2}=98.8 \% ; \mathrm{p} \leq 0.001\right)$ decreased the certainty of the evidence (figure 3 and online supplemental table 2).

\section{Prevalence of impaired glucose tolerance}

Fourteen studies covering 12604 adult participants and reporting prevalence of impaired glucose tolerance were included in this meta-analysis. ${ }^{60-73} \mathrm{Six}$ of these studies were conducted in Amhara region ${ }^{61-6365} 7072$ and three in

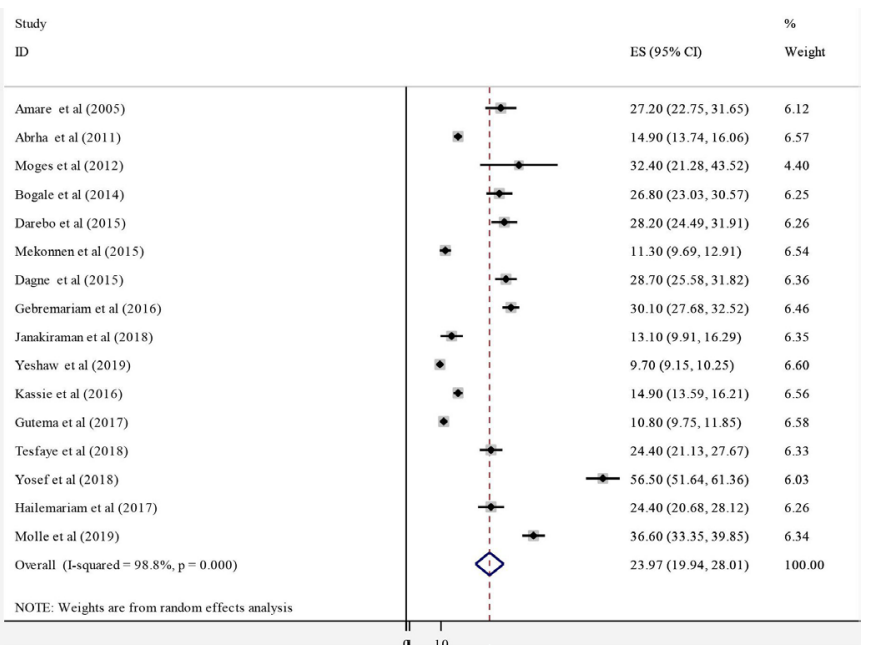

Figure 3 A forest plot of prevalence (\%) of overweight/ obesity among adults in Ethiopia. ES, effect size.

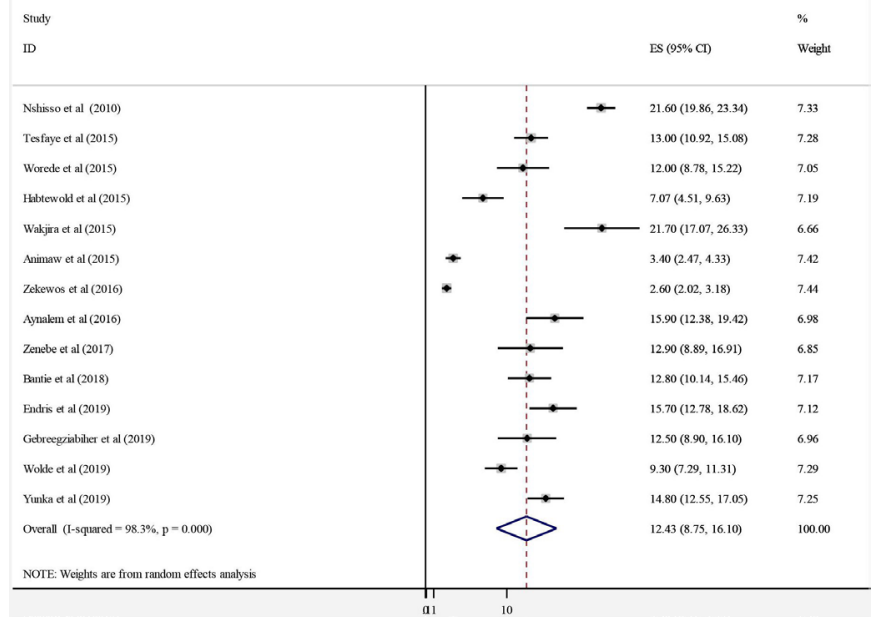

Figure 4 A forest plot of prevalence (\%) of impaired glucose tolerance among adults in Ethiopia. ES, effect size.

Addis Ababa. ${ }^{60668}$ The prevalence of impaired glucose tolerance ranged from $2.6 \%$ in Southern Ethiopia ${ }^{64}$ to 21.7\% in Addis Ababa. ${ }^{68}$ Overall, the pooled prevalence of impaired glucose tolerance was $12.4 \%$ (95\% CI $8.7 \%$ to $16.1 \%$, certainty of evidence: low), but there was heterogeneity among the included studies in this meta-analysis $\left(\mathrm{I}^{2}=98.3 \% ; \mathrm{p} \leq 0.001\right)$ (figure 4 and online supplemental table 3).

\section{Prevalence of metabolic syndrome}

Besides metabolic syndrome, 8 studies targeting 15932 adult participants which reported on prevalence of metabolic syndrome were included in this analysis. ${ }^{90-97}$ Three of the these studies ${ }^{909293}$ were from Addis Ababa, while the remaining were from Southern Ethiopia, ${ }^{94}$ Oromia, ${ }^{91} 97$ Dire Dawa ${ }^{96}$ and nationwide. ${ }^{95}$ Metabolic syndrome prevalence varied from $4.8 \%$ (95\% CI $1.73 \%$ to $7.87 \%$ ) based on national sample ${ }^{95}$ to $26 \%$ (95\% CI $19.61 \%$ to $32.39 \%$ ) in Oromia region. ${ }^{91}$ In this meta-analysis, the pooled prevalence of metabolic syndrome among Ethiopian adults was $14.7 \%$ (95\% CI $9.8 \%$ to $19.6 \%$, certainty of evidence: low). The high level of heterogeneity among the included studies $\left(\mathrm{I}^{2}=98.6 \% ; \mathrm{p} \leq 0.001\right)$ and publication bias downrated the certainty of evidence (figure 5 , online supplemental table 3 ).

\section{Subgroup analysis}

Subgroup analysis was performed to investigate sources of heterogeneity among the studies included in the pooled prevalence of metabolic risk factors using regions of study, years of study, settings of the study, and sample size. The subgroup analysis showed that the pooled prevalence of hypertension was $20.9 \%$ in studies done after $2010,21.4 \%$ in research conducted with study participants above 400 , $20.9 \%$ in studies performed at community level, $27.0 \%$ in studies done in Addis Ababa. The result of subgroup analysis also revealed the pooled prevalence of impaired glucose tolerance was $11.5 \%$ in studies done later 2010, and $12.9 \%$ in research done with sample size less than or 


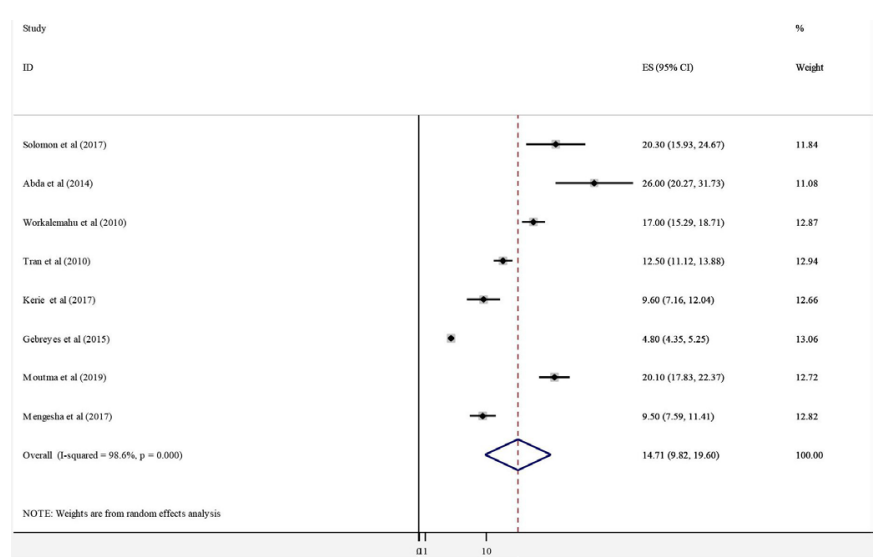

Figure 5 A forest plot of prevalence (\%) of metabolic syndrome among adults in Ethiopia. ES, effect size.

equal to $400,15.6 \%$ in studies conducted in institution, and $18.6 \%$ in studies done in Addis Ababa city administration. With regard to the pooled prevalence of overweight/obesity, it was $23.9 \%$ in research performed since 2010, 24.6\% in research done in Amhara region, 22.3\% in studies done at community level, and $38.6 \%$ in original studies conducted with study participants up to 400 . Similarly, the pooled prevalence of metabolic syndrome was $23.0 \%$ in research performed with study participants less than or equal to $400,14.7 \%$ in studies done in the last ten years, and $18.9 \%$ in studies performed in institutions (table 1).

\section{Publication bias}

The presence of publication bias was first assessed subjectively by observing the symmetrical distribution of the included studies in the funnel plot. The funnel plot test result showed that all the included studies in the pooled prevalence of metabolic risk factors were symmetrically distributed around the centre within the $95 \%$ confidence limits (figures 6-9). Then, Egger's test for funnel plot was conducted. The result of Egger's test for the funnel plot revealed that there was no publication bias in the included studies for the pooled prevalence of hypertension $(\mathrm{p}=0.411)$. But there was publication bias for the pooled prevalence of overweight/obesity, impaired glucose tolerance, and metabolic syndrome in the included studies ( $p<0.001$ for overweight/obesity, $p<0.001$ for impaired glucose tolerance, and $\mathrm{p}=0.005$ for metabolic syndrome) (online supplemental figures 1-4)

\section{Trim-and-fill analysis for the prevalence of metabolic risk factors}

Trim-and-fill analysis was conducted to adjust publication bias for pooled prevalence of metabolic risk factors with the estimation of number of missing studies that might exist. The result showed that there were no studies imputed for missing studies for the pooled prevalence of overweight/obesity. Whereas the trim and fill analysis revealed three studies were imputed for the pooled prevalence of impaired glucose tolerance and after adjustment the estimated pooled prevalence of impaired glucose tolerance was $10.5(7.2,13.7)$. While for the pooled prevalence of metabolic syndrome one studies was imputed for missing analysis and the estimated prevalence after adjustment was $13.3(8.7,17.9)$. Note that trim-and-fill analysis was not performed for hypertension since there was no publication bias among the included studies (online supplemental figures 5-7).

\section{Sensitivity analysis}

Besides, the subgroup analysis, publication bias and trim-and-fill analysis, we examined the effect of individuals studies on the overall pooled prevalence estimates of metabolic risk factors. However, the level of heterogeneity did not significantly reduce, when we compare the level heterogeneity by removing any one of single study or outliers, mainly studies having larger or smaller sample sizes.

\section{The association of the sex of participants and prevalence of metabolic risk factors}

To determine the association between metabolic risk factors and sex of participants log OR was used after identifying studies reported significant association between sex of participants and the prevalence metabolic risk factors. Overall, 18 hypertension studies, ${ }^{28-33} 354043-45484951555998$ 3 impaired glucose tolerance studies, ${ }^{646870} 7$ overweight/ obesity studies 748385868889 and 7 metabolic syndrome studies $^{90-9294-97}$ reported a significant link between prevalence and the sex of participants. The result of log OR's analysis revealed that the prevalence of hypertension, impaired glucose tolerance, and metabolic syndrome did not show significant difference between men and women. However, a significant difference was observed in the prevalence of overweight/obesity between men and women, with women having $60 \%$ higher chance of being overweight/obesity than men (Adjusted Odds Ratio (AOR) $0.41,95 \%$ CI 0.26 to 0.65 , certainty of evidence: low) (figure 10 and online supplemental table 3).

\section{The association of the age of participants and prevalence of metabolic risk factors}

Similarly, to determine the association of age of participants and the prevalence of metabolic risk factors log OR were calculated after identifying studies reporting significant associations between the age of participants and prevalence metabolic risk factors. Out of 36 studies on hypertension, 26 studies $^{25} 27$ 29-35 3738 40-48 505154 57-59 reported significant association between the age of the participants and the prevalence of hypertension. Similarly, nine studies $7476-788082848587$ on overweight/obesity, six studies ${ }^{60163646673}$ on impaired glucose tolerance, and six studies ${ }^{90194-97}$ on metabolic syndrome reported significant associations between the age of participants and the respective prevalence. The result of log OR showed that the prevalence of metabolic risk factors was significantly associated with the age of participants. The prevalence of hypertension was 3.4 times higher in people aged 45 years 
Table 1 Prevalence of metabolic risk factors among adults in Ethiopia grouped by characteristics of included studies

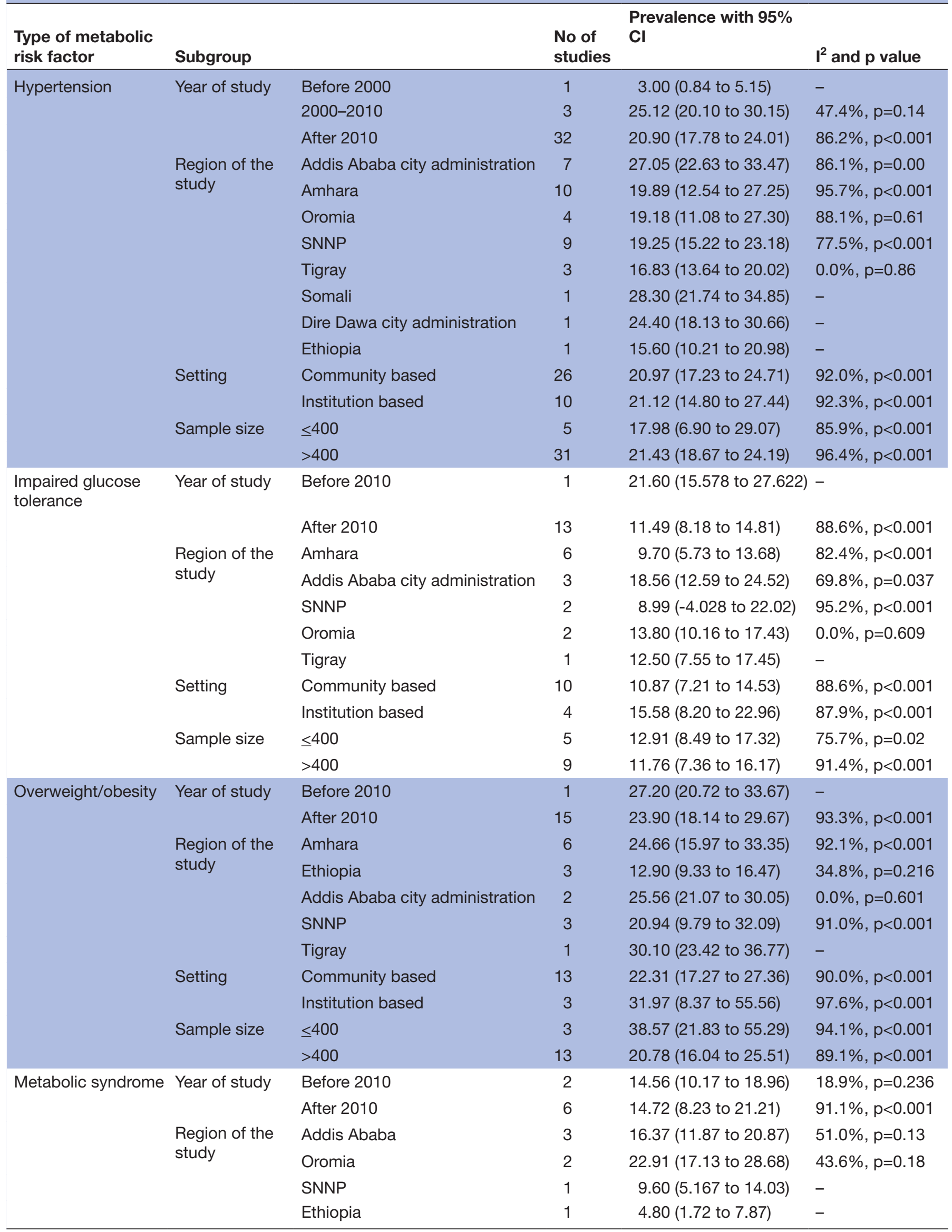


Table 1 Continued

\begin{tabular}{|c|c|c|c|c|c|}
\hline \multirow[b]{2}{*}{$\begin{array}{l}\text { Type of metabolic } \\
\text { risk factor }\end{array}$} & \multirow[b]{2}{*}{ Subgroup } & & \multirow[b]{2}{*}{$\begin{array}{l}\text { No of } \\
\text { studies }\end{array}$} & \multicolumn{2}{|l|}{ Prevalence with $95 \%$} \\
\hline & & & & & $I^{2}$ and $p$ value \\
\hline & & Dire Dawa city administration & 1 & 9.50 (5.08 to 13.91$)$ & \\
\hline & Setting & Community based & 3 & $7.63(4.22$ to 11.04$)$ & $55.6 \%, p=0.105$ \\
\hline & & Institution based & 5 & 18.93 (14.53 to 23.32$)$ & $66.3 \%, p=0.018$ \\
\hline & Sample size & $\leq 400$ & 2 & 23.01 (17.43 to 28.59 ) & $39.4 \%, p=0.19$ \\
\hline & & $>400$ & 6 & 11.91 (7.39 to16.42) & $83.0 \%, p \leq 0.001$ \\
\hline
\end{tabular}

Cl, confidence interval; SNNP, Southern Nations, Nationalities and Peoples Region.

and older than people below 45 years old (AOR 3.4, 95\% CI 2.6 to 4.2 , certainty of evidence: moderate). The prevalence of overweight/obesity was 1.6 times higher among people above 45 years old than participants below 45 years old (AOR 1.6, 95\% CI 1.1 to 2.4, certainty of evidence: low). Similarly, impaired glucose tolerance (AOR 2.6, 95\% CI 1.4 to 4.8 , certainty of evidence: low) and metabolic syndrome (AOR 3.3, 95\% CI 2.2 to 4.7 , certainty of evidence: low) were significantly higher among people above 45 years old (figure 11, online supplemental table 3).

\section{DISCUSSION}

To the best of our knowledge, this is the first systematic review and meta-analysis to comprehensively examine the prevalence estimates of metabolic risk factors for NCDs in Ethiopia. There was one review ${ }^{98}$ reporting the pooled prevalence of hypertension, but the evidence had low certainty due to inconsistency and publication bias and was conducted more than 5 years ago and considered all adults irrespective of coexisting conditions. Given the lack of comprehensive evidence on risk factors of NCDs at national level, this review targeted metabolic risk factors for NCDs in Ethiopia. The findings of this review are likely to inform future policy decisions.

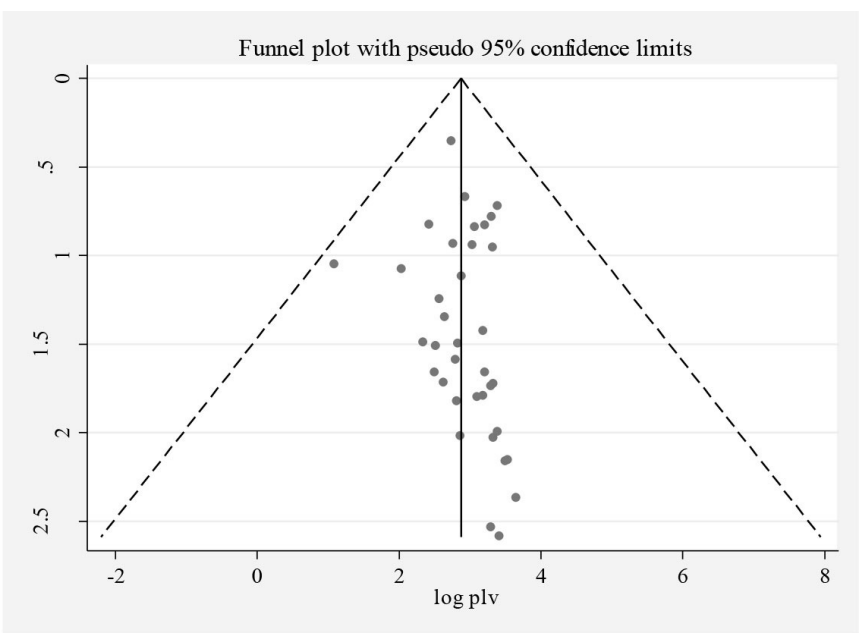

Figure 6 Distribution of studies included in hypertension analysis in the funnel graph.
The WHO estimated that more than one-third of the burden of disease in Ethiopia can be attributed to NCDs, and an estimated $43 \%$ of deaths in 2019 were caused by NCDs. ${ }^{4}$ Metabolic risk factors are major contributors to global burden of diseases and are immediate indicators for the incidence of NCDs, ${ }^{5}$ especially for cardiovascular diseases and diabetes, which warrants particular public measures considering the burden variation based on region, gender and age. ${ }^{59}$ This study revealed a high prevalence of metabolic risk factors for NCDs in Ethiopia-nearly one in five participants suffer from at least one of the studied metabolic risk factors (hypertension, overweight/obesity, impaired glucose tolerance and metabolic syndrome). These metabolic risk factors are associated with, and reinforced by, behavioural risk factors such as alcohol consumption, tobacco smoking, poor dietary habits and physical inactivity. ${ }^{2}$ The high level of poverty, and unemployment could also contribute to the metabolic risk factors. ${ }^{100-102}$ Therefore, the high prevalence of the metabolic predictors for NCDs in this study potentially indicate the presence of various behavioural and environmental stressors underlying these conditions that need to be examined in future studies.

In this study, we found a $21 \%$ pooled prevalence of hypertension (certainty of evidence: moderate), which

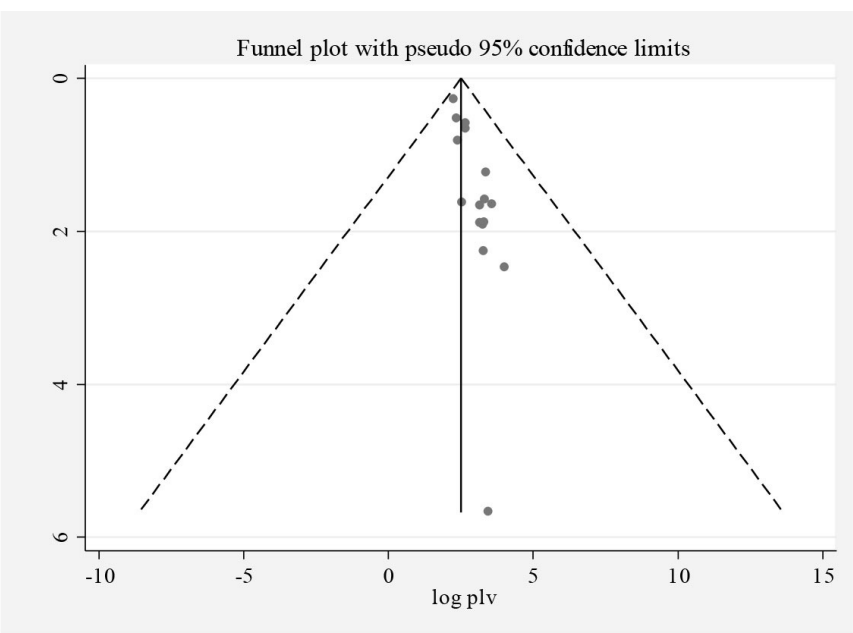

Figure 7 Distribution of studies included in overweight/ obesity analysis in the funnel graph. 


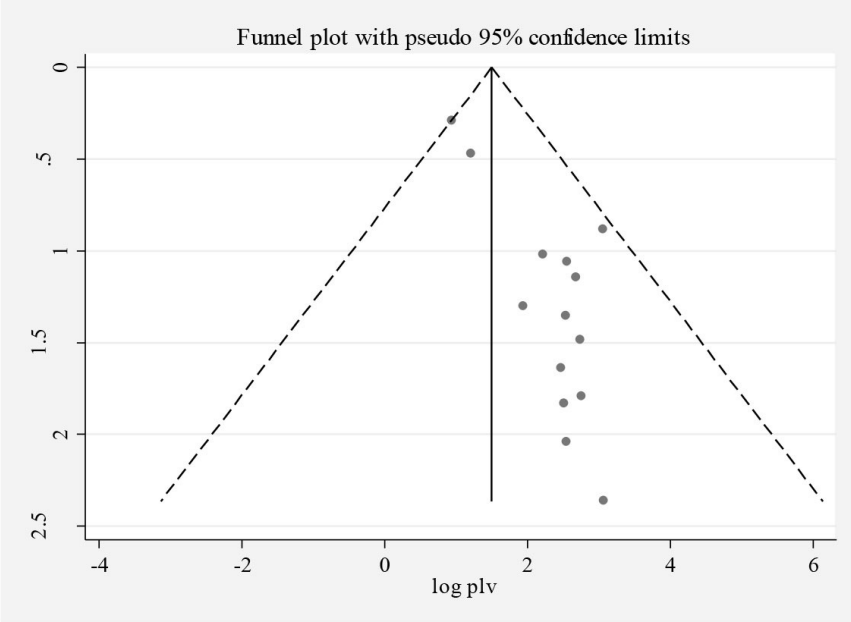

Figure 8 Distribution of studies included in impaired glucose tolerance in the funnel graph.

is slightly higher than the $19 \%$ reported in a previous relatively smaller review in Ethiopia, ${ }^{98}$ but slightly lower than the $24 \%$ prevalence reported by the WHO. ${ }^{103}$ Also, this pooled prevalence is lower than the prevalence $(57 \%)$ reported in older adults from multiple African countries $^{104}$ or the prevalence $(32.3 \%)$ of hypertension reported in LMICs collectively ${ }^{105}$, although the quality of evidence in these reviews vary from poor to moderate due to incosistency of included studies. The difference with the report in LMICs is explained in their subgroup analysis of pooled prevalence of hypertension by income levels of countries that the pooled prevalence was $38 \%$ for upper-middle-income countries and 23\% for low-income countries. Regarding the study in African countries, ${ }^{104}$ the higher prevalence could be due to the inclusion of older cohort, a population group already at high risk of raised $\mathrm{BP}$. Also, the prevalence of smoking ${ }^{106}$ and alcohol consumption ${ }^{107}$ is lower in Ethiopia compared with the rest of Africa. Although the exact causes of hypertension in Ethiopia are not entirely understood, several factors such as smoking, overweight or obesity, physical inactivity,

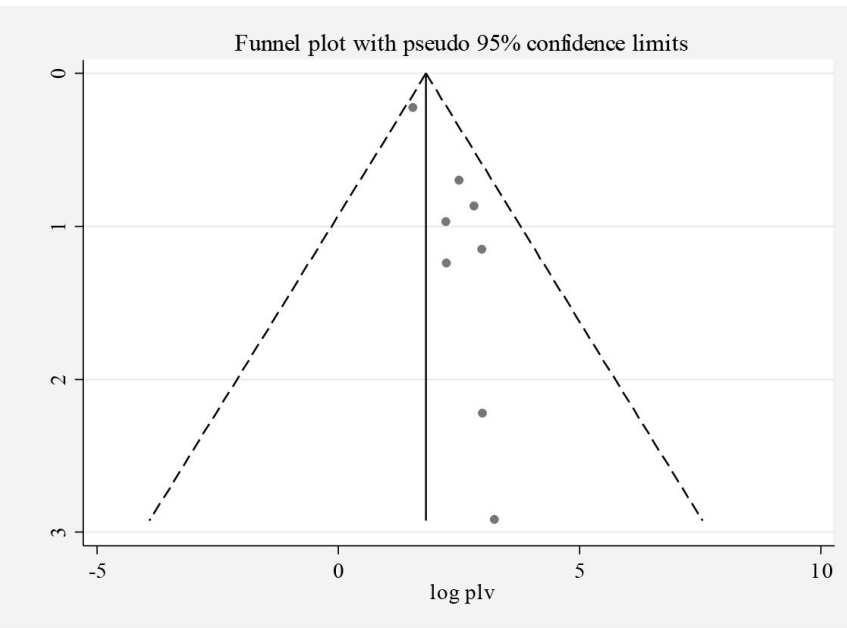

Figure 9 Distribution of studies included in metabolic syndrome analysis in the funnel graph. high salt intake and alcohol consumption habits would have undeniable role for the reported high prevalence. Also, other factors like stress, increased age, urbanisation, and genetics could contribute to the reported prevalence of high BP.

Our findings also indicate that, although the certainty of evidence is low, the pooled prevalence of overweight and obesity was $23.9 \%$, which is lower than the global prevalence $(39 \%)^{108}$ but higher than the prevalence of overweight $(15.9 \%)$ reported in demographic health survey analysis of 32 sub-Saharan African countries having a moderate quality of evidence ${ }^{109}$ and from the 2011 Ethiopian demographic health survey reported prevalence $(12 \%)$ in urban women. ${ }^{76}$ Poor diet intake including high levels of simple carbohydrates, increased caloric consumption, use of medications, reduced physical activity and other psychosocial factors are among the predictors of overweight/obesity that could also be applicable in the Ethiopian context. In addition, although not considered in this study, early age malnutrition (including undernutrition) causes metabolic abnormalities like hypothyroidism and insulin resistance later in life and thus could contribute to the increasing overweight and obesity in the country. ${ }^{110} 111$ Therefore, due attention should be given to the potentially modifiable determinants of overweight or obesity to mitigate the subsequent risk of NCDs earlier in life.

This study further showed that the pooled prevalence of impaired glucose tolerance in Ethiopia was $12.4 \%$. This finding is higher than the prevalence $(9.1 \%)$ reported in 2015 national NCDs survey, ${ }^{95}$ the pooled prevalence $(6.0 \%)$ among childbearing age women in sub-Saharan Africa ${ }^{112}$; comparable to the prevalence $(12.0 \%)$ of impaired glucose homoeostasis in sub-Saharan Africa having a moderate quality of evidence $;{ }^{113}$ and lower than the prevalence $(22.1 \%)$ reported in patients with aldosteronism with a low quality of evidence. ${ }^{114}$ The differences may have occurred due to methodological variations, participants characteristics and the available evidence in respective settings. Nevertheless, our finding is a stark reminder on the burden of impaired glucose tolerance putting significant proportion of the adult population at greater risk of DM and other complications. This underlines the need to adequately and timely manage factors that contribute to impaired glucose tolerance, including less physical inactivity (sedentary lifestyle), overweight or obesity, family history of DM, history of high BP and high cholesterol.

We found a $15 \%$ pooled prevalence for metabolic syndrome in this study with the overall low quality of the evidence. This is much higher than a national NCDs survey that reported $4.8 \%$ prevalence $^{95}$ and comparable to a $16 \%$ pooled prevalence among HIV patients although the certainty of evidence was very low. ${ }^{15}$ Higher prevalence were reported, despite the quality of the evidence was low, in people with psychiatric disorders $(19 \%)^{116}$ and arthritis $(30.5 \%) .{ }^{117}$ The differences in the prevalence among the studies could be explained by the fact that we 


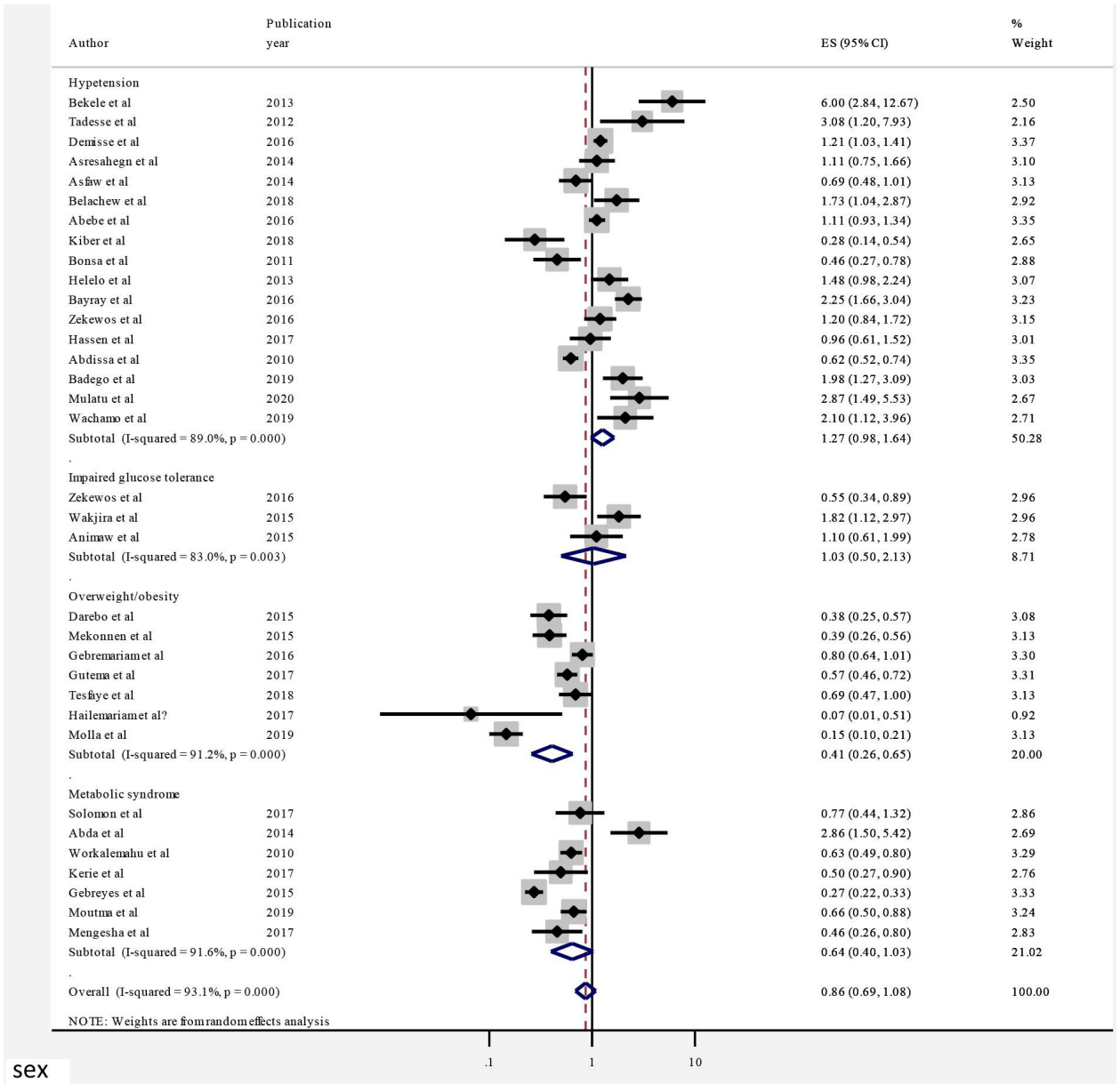

only considered healthy adult populations without any underlining health conditions in this study, which could have underestimated the magnitude of the burden in the community.

High levels of triglycerides and metabolic syndromes cause significant proportion of heart diseases thereby contributing to the ever-increasing prevalence of NCDs in LMICs and high-income countries alike. ${ }^{2}$ This is because of the thickening and hardening of the walls of blood vessels (arteries), which are most of the time associated with poorly controlled obesity/diabetes and improper feeding of saturated fat, sugar, salty foods and limited intake of fruits and vegetables. ${ }^{118}$ Poor diet with high-fat content and highly refined, processed foods like sugars, white bread and dry cereals are associated with greater risks of developing insulin resistance and all other aspects of the metabolic syndrome. ${ }^{119}$ Thus, it is important to educate people on the value of healthy diets (which are low in cholesterol, sodium and sugar contents), staying physically active, quitting smoking and decreasing alcohol intake to reduce metabolic syndrome and its long-term consequences.

Finally, notwithstanding the low-quality evidence to support associations, metabolic risk factors showed variation based on gender-the overall risk appeared to be higher in women. This may seem counterintuitive given some behavioural risk factors like smoking and alcohol consumption, which are often associated with metabolic risk factors like high BP, are more common in men. ${ }^{120}$ In contrast, there are studies showing the greater tendency of physical inactivity or sedentary lifestyle among women. ${ }^{121}$ Nevertheless, a similar trend was observed in Tanzania, where women had a higher prevalence of obesity, and metabolic syndrome. ${ }^{122}$ Consistent with our findings, a previous study also indicated that obesity is more common among women, ${ }^{120}$ whereas, another study showed men in some LMICs tended to be physically more active. ${ }^{121}$ These findings, collectively, suggest that the metabolic risk factors, particularly overweight/obesity, are more common in women, highlighting their increased risk for NCDs. Irrespective of the causes, the findings highlight the need to address this problem through addressing behavioural risk factors that cause metabolic disorders and promoting community screening for early detection of the conditions. Given the link between socioeconomic status and NCDs, ${ }^{123124}$ strategies aimed at addressing socioeconomic disparities could help mitigate factors contributing to 


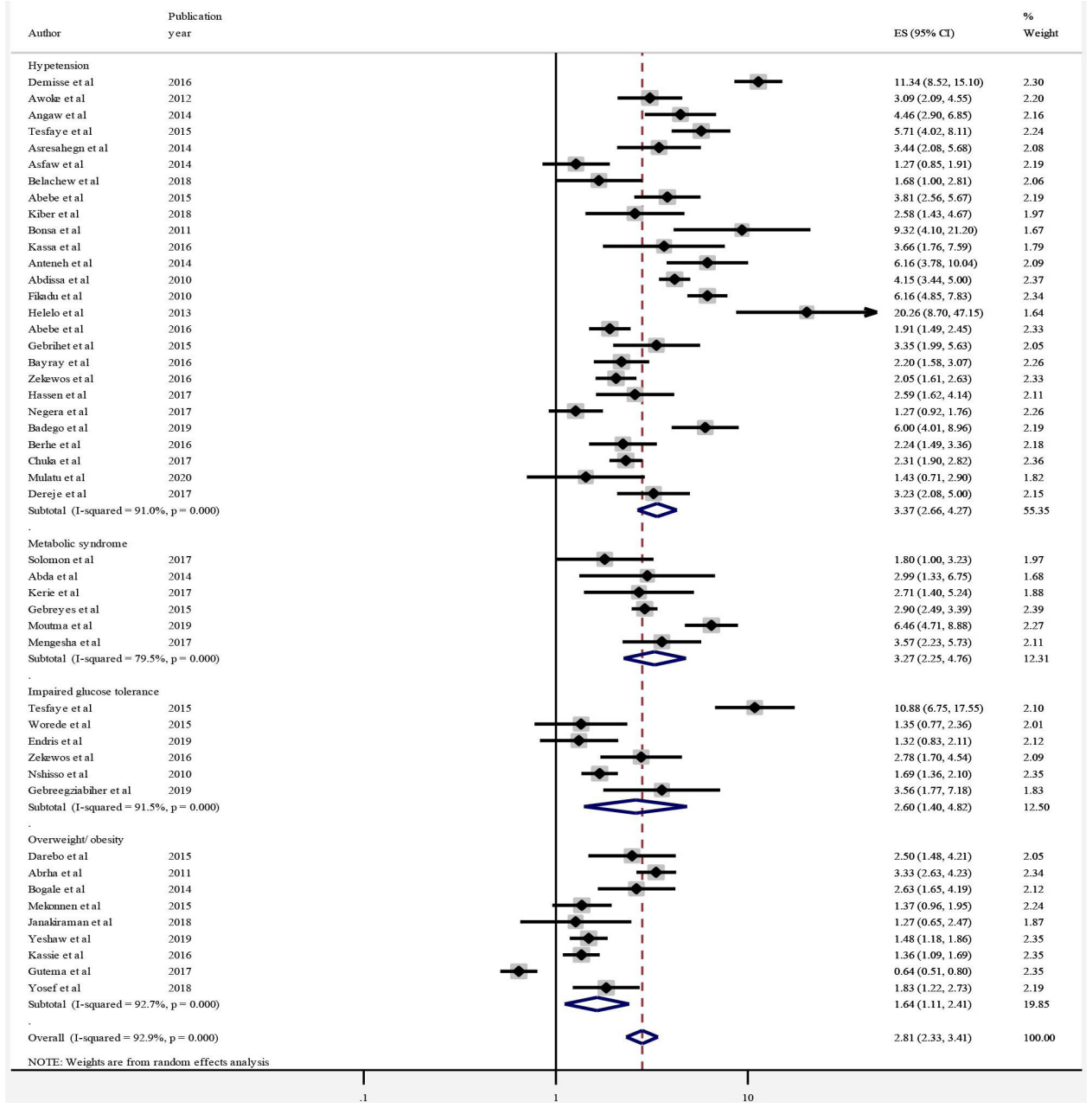

Figure 11 A forest plot of the association of age of participant with the prevalence of metabolic risk factors in Ethiopia (people under the age of 45 years as a reference). ES, effect size.

stressful life events thereby reducing high BP and subsequent NCDs.

\section{Implications for practice}

Metabolic risk factors are immediate precursor of NCDs which results in mortalities, disabilities and decrease in quality of life. Preventing and managing these risk factors is of public health importance. This review highlighted the high prevalence of metabolic risk factors among adults, although based on limited certainty of evidence, alerts healthcare workers, healthcare institutions and the government to focus on prevention activities to reduce these risk factors in the community.

This study informs primary healthcare providers and public health workers who are working in the community to consider preventions to reduce metabolic risk factors of NCDs in adults. The current primary healthcare programmes in the country hugely focus on maternal and child health programmes. However, over the past three decades, NCDs have been increasing rapidly, warranting further research into the causes and strategies to rectify them. Lifestyle education and health promotion strategies mainly aiming at modifying behavioural risk factors for
NCDs can be instrumental in realising the national and global targets. Therefore, primary healthcare providers need to be involved in awareness creation programmes through health education, community-based screening, identification and referral of cases that need healthcare interventions like hypertension and diabetes. Working with adult and youth centres, campaigning and awareness creation can also help to reduce these risk factors in the community. This review showed metabolic risk factors were more common in women and older adults. Thus, considering targeted approaches tailored for these segments of the community during prevention activities will potentially result in positive outcomes.

Healthcare workers in hospitals and health centres should consider screening for metabolic risk factors for adults at least by measuring height, weight, BP and blood glucose levels for all adults along with screening for behavioural risk factors such as physical inactivity, dietary habits, tobacco usage and alcohol consumption. It is important to include topics related to metabolic risk factors for people who come to the health facilities in the morning health education programmes. Follow-up and 
counselling should be also considered for peoples who are found to have metabolic risk factors. Besides, proper training for healthcare providers increases their ability to diagnose and manage metabolic risk factors and prevent NCDs.

This study informs the regional government to prepare management guidelines to revert the rise of metabolic risk factors to decrease the burden of NCDs. Regional and national health programmes should consider NCDs preventions as one of their majors by designing appropriate interventions such as by preparing protocols and guidelines, equipping primary healthcare setups with human power, resource and making accessible for the community. The government of Ethiopia should also consider strategies working on social determinants of health, such as urban planning, education, employment and public safety which help to reduce risk behaviours to reduce burden metabolic risk factors. Further, it is important to have proper programme evaluation in place to oversee implementation of strategies.

\section{Recommendations for future research}

Based on the result of this review, the following recommendation are drawn for future research and researchers.

This review showed that most studies used relatively small sample sizes to represent the community, most of which were conducted targeting less than a thousand participants. Although they were statistically representative of the community, we recommend large scale surveys to guide public health interventions and inform decision making. Nearly all studies were cross-sectional in nature that showed the problem at a specific point in time. Thus, long-term studies, such as prospective follow-up cohorts can help to identify the causes of metabolic risk factors in the community.

No intervention has been tested to reduce the metabolic risk factors in Ethiopia. Thus, to identify feasible and effective interventions researchers should consider randomised control trials. Community-based interventional studies help to inform the government interventions that are effective to reduce metabolic risk factors. In addition, studies are needed to understand behavioural factors that contribute metabolic risk factors to design and implement appropriate interventions.

Demographic factors such as gender and age were found to be associated with metabolic risk factors. They are currently the main research and public health agenda in many countries. We also recommend Ethiopian researchers to assess the social gradients of health such as gender, age, education, occupation, income, housing, physical and social environment, public safety, transportation and access to healthcare.

\section{Strengths and limitations}

This review is the first of its nature combining studies with similar characteristics in the context of metabolic risk factors for NCDs in Ethiopia in a single study. Despite the review lacking a protocol registered a priori, we strictly adhered to the PRISMA guidelines during the design, conducting and reporting of our findings to increase robustness of the methods. The review uses prevalence studies to estimate the level of metabolic risk factors in adults, and most of the included studies had low risk of bias. The number of participants incorporated in this review was more than a hundred thousand. Thus, our prevalence estimate will fairly represent the adult population in Ethiopia. Furthermore, the study tried to show age and sex differences of metabolic risk factors distributions, make our result easy to understand, interpret, put in action.

Although most of the included studies in this review had low risk of bias to represent prevalences of metabolic risks among adults in Ethiopia, the overall certainty of the evidence is considerably low due to heterogeneity of the included studies and poor methodolgical design. Besides, we did not find studies conducted in Afar, BenishangulGumuz, Gambella regions, so our prevalence estimates might not precisely reflect the real situations in these regions. Moreover, the heterogeneity among the included studies precluded us from performing further analyses to identify individual study and clinical factors contributing to metabolic risk factors.

\section{CONCLUSION}

This systematic review and meta-analysis revealed a high proportion of metabolic risk factors in Ethiopian adults. The review summarised pooled prevalences of overweight/obesity (24\%), hypertension (21\%), metabolic syndrome $(15 \%)$ and impaired glucose tolerance $(12 \%)$. All metabolic risks were higher in older adults, while overweight/obesity appeared to be higher in females. Despite most of included studies having low risk of bias, the quality of the overall evidence was low due to signficant heterogeneity between studies, and the small number included studies precluded detailed analysis of the associations. Since metabolic risk factors are immediate precursors for NCDs, they need to be managed and, when possible, reversed to reduce NCDs incidences and long-term consequences on health-related quality of life and other health outcomes. These results are important reminders of the need to effectively implement the multilayered strategies proposed by the Ethiopian government, including strengthening national health policy on NCDs and their risk factors, strengthening national and regional NCDs units, and raising awareness on the burden of these diseases among health workers and the wider community. It also highlights the need to tailor preventative interventions in high-risk populations like older adults and women. Further, it is important to have proper programme evaluation in place to oversee the implementation of the strategies. Lifestyle education and health promotion strategies mainly aiming at modifying behavioural risk factors for NCDs can be instrumental in realising the national and global targets. This study will inform the regional government to prepare management 
guidelines to significantly reduce the rise of metabolic risk factors to decrease the burden of NCDs, and for researchers to consider community-based interventional studies.

Contributors TTA and MK conceived the study. TTA and WT searched and extracted data, assessed the quality, analysed, interpreted the result and drafted the manuscript; MK and SA critically reviewed the draft manuscript for intellectual content and developed the final version. All authors read and approved this manuscript. TTA is the guarantor for the study.

Funding The authors have not declared a specific grant for this research from any funding agency in the public, commercial or not-for-profit sectors.

Disclaimer The information provided in this manuscript entirely represents the authors.

Competing interests None declared.

Patient consent for publication Not applicable.

Ethics approval This study is a systematic review and meta-analysis based entirely on the review of existing literature. No human participants or patients were involved in the design and conduct this review. Therefore, ethics approval and consent to participate would not be applicable for this study.

Provenance and peer review Not commissioned; externally peer reviewed.

Data availability statement All data relevant to the study are included in the article or uploaded as online supplemental information. All data relevant to the study are included in the manuscript.

Supplemental material This content has been supplied by the author(s). It has not been vetted by BMJ Publishing Group Limited (BMJ) and may not have been peer-reviewed. Any opinions or recommendations discussed are solely those of the author(s) and are not endorsed by BMJ. BMJ disclaims all liability and responsibility arising from any reliance placed on the content. Where the content includes any translated material, BMJ does not warrant the accuracy and reliability of the translations (including but not limited to local regulations, clinical guidelines, terminology, drug names and drug dosages), and is not responsible for any error and/or omissions arising from translation and adaptation or otherwise.

Open access This is an open access article distributed in accordance with the Creative Commons Attribution Non Commercial (CC BY-NC 4.0) license, which permits others to distribute, remix, adapt, build upon this work non-commercially, and license their derivative works on different terms, provided the original work is properly cited, appropriate credit is given, any changes made indicated, and the use is non-commercial. See: http://creativecommons.org/licenses/by-nc/4.0/.

ORCID iDs

Tilahun Tewabe Alamnia http://orcid.org/0000-0001-9674-2495

Wubshet Tesfaye http://orcid.org/0000-0001-7208-2330

Matthew Kelly http://orcid.org/0000-0001-7963-2139

\section{REFERENCES}

1 GBD 2017 Causes of Death Collaborators. Global, regional, and national age-sex-specific mortality for 282 causes of death in 195 countries and territories, 1980-2017: a systematic analysis for the global burden of disease study 2017. Lancet 2018;392:1736-88.

2 World Health Organization. Global status report on noncommunicable diseases 2014. World Health Organization, 2014

3 Alwan A. Global status report on noncommunicable diseases 2010. World Health Organization, 2011.

4 World Health Organization. Global health estimates 2019. WHO, 2020.

5 GBD 2017 Risk Factor Collaborators. Global, regional, and national comparative risk assessment of 84 behavioural, environmental and occupational, and metabolic risks or clusters of risks for 195 countries and territories, 1990-2017: a systematic analysis for the global burden of disease study 2017. Lancet 2018;392:1923-94.

6 Saeedi P, Petersohn I, Salpea P. Global and regional diabetes prevalence estimates for 2019 and projections for 2030 and 2045: results from the International diabetes Federation diabetes atlas. 9th edn. Diabetes Research and Clinical Practice, 2019.

7 WHO. NCD and the sustainable development goals. Available: https://www.who.int/global-coordination-mechanism/ncd-themes/ sustainable-development-goals/en/
8 Organization WH. Global action plan for the prevention and control of noncommunicable diseases 2013-2020. World Health Organization, 2013.

9 Ethiopia Ministry of Health. Guidelines on clinical and programmatic management of major non communicable diseases. Ethiopia Ministry of Health, 2016.

10 Liberati A, Altman DG, Tetzlaff J, et al. The PRISMA statement for reporting systematic reviews and meta-analyses of studies that evaluate health care interventions: explanation and elaboration. $J$ Clin Epidemiol 2009;62:e1-34.

11 Covidence. Cochrane community, 2020. Available: https://www. covidence.org/reviewers [Accessed 05 Apr 2021].

12 Aromataris E, Munn Z, eds. JBI Manual for evidence synthesis, 2020. https://synthesismanual.jbi.global

13 The Joanna Briggs Institute critical appraisal tools for use in JBI systematic reviews checklist for analytical cross sectional studies. Available: http://joannabriggs.org/research/critical-appraisal-tools. html

14 World Health Organisation. Obesity and overweight. Geneva: WHO, 2020. https://www.who.int/news-room/fact-sheets/detail/obesityand-overweight

15 Rao SS, Disraeli P, McGregor T. Impaired glucose tolerance and impaired fasting glucose. Am Fam Physician 2004;69:1961-8.

16 World Health Organization. A global brief on hypertension: silent killer, global public health crisis: World Health Day. World Health Organization, 2013.

17 Expert Panel on Detection, Evaluation, and Treatment of High Blood Cholesterol in Adults. Executive summary of the third report of the National cholesterol education program (NCEP) expert panel on detection, evaluation, and treatment of high blood cholesterol in adults (adult treatment panel III). JAMA 2001;285:2486.

18 Alberti KGMM, Zimmet P, Shaw J, et al. The metabolic syndrome-a new worldwide definition. Lancet 2005;366:1059-62.

19 Langan D, Higgins JPT, Jackson D, et al. A comparison of heterogeneity variance estimators in simulated random-effects meta-analyses. Res Synth Methods 2019;10:83-98.

20 Kirmayr M, Quilodrán C, Valente B, et al. The GRADE approach, part 1: how to assess the certainty of the evidence. Medwave 2021;21:e8109.

21 Borenstein M, Hedges LV, Higgins JPT, et al. A basic introduction to fixed-effect and random-effects models for meta-analysis. Res Synth Methods 2010;1:97-111.

22 Egger M, Davey Smith G, Schneider M, et al. Bias in meta-analysis detected by a simple, graphical test. BMJ 1997;315:629-34.

23 Guyatt G, Oxman AD, Akl EA, et al. GRADE guidelines: 1. Introduction-GRADE evidence profiles and summary of findings tables. J Clin Epidemiol 2011;64:383-94.

24 Tesfaye F, Byass P, Wall S. Population based prevalence of high blood pressure among adults in Addis Ababa: uncovering a silent epidemic. BMC Cardiovasc Disord 2009;9:39.

25 Awoke A, Awoke T, Alemu S, et al. Prevalence and associated factors of hypertension among adults in Gondar, Northwest Ethiopia: a community based cross-sectional study. BMC Cardiovasc Disord 2012;12:113.

26 Mengistu MD. Pattern of blood pressure distribution and prevalence of hypertension and prehypertension among adults in Northern Ethiopia: disclosing the hidden burden. BMC Cardiovasc Disord 2014;14:33.

27 Angaw K, Dadi AF, Alene KA. Prevalence of hypertension among federal ministry civil servants in Addis Ababa, Ethiopia: a call for a workplace-screening program. BMC Cardiovasc Disord 2015;15:76.

28 Tadesse T, Alemu H. Hypertension and associated factors among university students in Gondar, Ethiopia: a cross-sectional study. BMC Public Health 2014;14:937.

29 Demisse AG, Greffie ES, Abebe SM, et al. High burden of hypertension across the age groups among residents of Gondar City in Ethiopia: a population based cross sectional study. BMC Public Health 2017;17:647.

30 Asresahegn H, Tadesse F, Beyene E. Prevalence and associated factors of hypertension among adults in Ethiopia: a community based cross-sectional study. BMC Res Notes 2017;10:629.

31 Asfaw LS, Ayanto SY, Gurmamo FL. Hypertension and its associated factors in Hosanna town, Southern Ethiopia: community based cross-sectional study. BMC Res Notes 2018;11:306.

32 Belachew A, Tewabe T, Miskir Y, et al. Prevalence and associated factors of hypertension among adult patients in Felege-Hiwot comprehensive referral hospitals, northwest, Ethiopia: a crosssectional study. BMC Res Notes 2018;11:876.

33 Abebe S, Yallew WW. Prevalence of hypertension among adult outpatient clients in hospitals and its associated factors in Addis 
Ababa, Ethiopia: a hospital based cross-sectional study. BMC Res Notes 2019:12:87.

34 Kiber M, Wube M, Temesgen $\mathrm{H}$, et al. Prevalence of hypertension and its associated factors among adults in Debre Markos Town, Northwest Ethiopia: community based cross-sectional study. BMC Res Notes 2019;12:406.

35 Bonsa F, Gudina EK, Hajito KW. Prevalence of hypertension and associated factors in Bedele Town, Southwest Ethiopia. Ethiop $J$ Health Sci 2014;24:21-6.

36 Gudina EK, Michael Y, Assegid S. Prevalence of hypertension and its risk factors in Southwest Ethiopia: a hospital-based crosssectional survey. Integr Blood Press Control 2013;6:111.

37 Kassa A, Woldesemayat EM. Hypertension and diabetes mellitus among patients at Hawassa university comprehensive specialized Hospital, Hawassa, southern Ethiopia. Int J Chronic Dis 2019;2019:2509242.

38 Anteneh ZA, Yalew WA, Abitew DB. Prevalence and correlation of hypertension among adult population in Bahir Dar City, Northwest Ethiopia: a community based cross-sectional study. Int J Gen Med 2015;8:175

39 Roba HS, Beyene AS, Mengesha MM, et al. Prevalence of hypertension and associated factors in dire Dawa City, eastern Ethiopia: a community-based cross-sectional study. Int J Hypertens 2019;2019:9878437.

40 Helelo TP, Gelaw YA, Adane AA. Prevalence and associated factors of hypertension among adults in Durame town, southern Ethiopia. PLoS One 2014;9:e112790.

41 Abebe SM, Berhane Y, Worku A, et al. Prevalence and associated factors of hypertension: a crossectional community based study in Northwest Ethiopia. PLoS One 2015;10:e0125210.

42 Gebrihet TA, Mesgna KH, Gebregiorgis YS, et al. Awareness, treatment, and control of hypertension is low among adults in Aksum town, Northern Ethiopia: a sequential quantitative-qualitative study. PLoS One 2017;12:e0176904.

43 Bayray A, Meles KG, Sibhatu Y. Magnitude and risk factors for hypertension among public servants in Tigray, Ethiopia: a crosssectional study. PLoS One 2018;13:e0204879.

44 Zekewos A, Egeno T, Loha E. The magnitude of hypertension and its risk factors in southern Ethiopia: a community based study. PLoS One 2019;14:e0221726.

45 Hassen B, Mamo H. Prevalence and associated anthropometric and lifestyle predictors of hypertension among adults in Kombolcha town and suburbs, Northeast Ethiopia: a communitybased cross-sectional study. BMC Cardiovasc Disord 2019;19:241

46 Negera E, Sileshi T, Hathic R. Magnitude and associated factors of hypertension among adults in illubabore zone of oromia national regional state, South West Ethiopia 2018;17.

47 Fikadu G, Lemma S. Socioeconomic status and hypertension among teachers and bankers in Addis Ababa, Ethiopia. Int $J$ Hypertens 2016;2016:4143962.

48 Abdissa SG, Feleke Y, Awol M. Prevalence of hypertension and pre-hypertension in Addis Ababa, Ethiopia: a survey done in recognition of World hypertension day, 2014. Ethiop J Health Dev 2015;29:22-30.

49 Bekele A, Gelibo T, Amenu K. The hidden magnitude of raised blood pressure and elevated blood glucose in Ethiopia: a call for initiating community based NCDS risk factors screening program. Ethiop $J$ Health Develop 2017;31:362-9.

50 Tesfaye TD, Temesgen WA, Kasa AS, et al. Prevalence and associated factors of hypertension in Amhara regional state city and its' surrounding rural districts: a community-based cross-sectional study. Afr Health Sci 2019;19:2580-90.

51 Badego B, Yoseph A, Astatkie A. Prevalence and risk factors of hypertension among civil servants in Sidama zone, South Ethiopia. PLoS One 2020;15:e0234485.

52 Yadecha B, Tekle F, Fetensa G, et al. Prevalence of hypertension and its associated factors among Gimbi town residents, Ethiopia: a community-based cross-sectional study. Integr Blood Press Control 2020;13:171.

53 Beall CM, Gebremedhin A, Brittenham GM, et al. Blood pressure variation among Ethiopians on the Simien plateau. Ann Hum Biol 1997;24:333-42.

54 Berhe DA, Yenit MK, Baraki AG. The burden of hypertension and associated factors among adults visiting the adult outpatient department at Yekatit 12 hospital medical College, Addis Ababa, Ethiopia, 2016. Vasc Health Risk Manag 2020;16:545-52.

55 Wachamo D, Geleta D, Woldesemayat EM. Undiagnosed hypertension and associated factors among adults in Hawela Tula Sub-City, Hawassa, southern Ethiopia: a community-based crosssectional study. Risk Manag Healthc Policy 2020;13:2169.
56 Haye TB, Tolera Agama B. Prevalence of hypertension and associated factors among the outpatient department in Akaki Kality Subcity health centers, Addis Ababa, Ethiopia. Int J Hypertens 2020;2020:7960578

57 Chuka A, Gutema BT, Ayele G, et al. Prevalence of hypertension and associated factors among adult residents in Arba Minch Health and demographic surveillance site, southern Ethiopia. PLoS One 2020;15:e0237333.

58 Dereje N, Earsido A, Temam L, et al. Uncovering the high burden of hypertension and its predictors among adult population in Hosanna town, southern Ethiopia: a community-based cross-sectional study. BMJ Open 2020;10:e035823.

59 Factors associated with hypertension among age groups of 18 years and above in, southwestern, Ethiopia, 2020: a community based cross-sectional. Diversity Equality Health Care 2020;17:202-8.

60 Tesfaye T, Shikur B, Shimels T, et al. Prevalence and factors associated with diabetes mellitus and impaired fasting glucose leve among members of federal police commission residing in Addis Ababa, Ethiopia. BMC Endocr Disord 2016;16:68.

61 Worede A, Alemu S, Gelaw YA, et al. The prevalence of impaired fasting glucose and undiagnosed diabetes mellitus and associated risk factors among adults living in a rural Koladiba town, Northwest Ethiopia. BMC Res Notes 2017;10:251.

62 Bantie GM, Wondaye AA, Arike EB, et al. Prevalence of undiagnosed diabetes mellitus and associated factors among adult residents of Bahir Dar City, Northwest Ethiopia: a community-based cross-sectional study. BMJ Open 2019:9:e030158.

63 Endris T, Worede A, Asmelash D. Prevalence of diabetes mellitus, prediabetes and its associated factors in Dessie town, northeast Ethiopia: a community-based study. Diabetes Metab Syndr Obes 2019;12:2799-809.

64 Zekewos A, Loha E, Egeno T, et al. Prevalence of diabetes mellitus and associated factors in southern Ethiopia: a community based study. Ethiop J Health Sci 2018;28:451-60.

65 Habtewold TD, Tsega WD, Wale BY. Diabetes mellitus in outpatients in Debre Berhan referral hospital, Ethiopia. J Diabetes Res 2016;2016:3571368.

66 Nshisso LD, Reese A, Gelaye B, et al. Prevalence of hypertension and diabetes among Ethiopian adults. Diabetes Metab Syndr 2012;6:36-41.

67 Aynalem SB, Zeleke AJ. Prevalence of diabetes mellitus and its risk factors among individuals aged 15 years and above in Mizan-Aman town, Southwest Ethiopia, 2016: a cross sectional study. Int $J$ Endocrinol 2018;2018:9317987.

68 Wakjira ZN, Beyene Berha A. Screening employees for undiagnosed type 2 diabetes mellitus and evaluation of risk scores in Tikur Anbessa specialized Hospital, Addis Ababa, Ethiopia. J Diabetes Metab 2017;08:2155-6.

69 Zenebe T, Merga H, Habte E. A community-based cross-sectional study of magnitude of dysglycemia and associated factors in Southwest Ethiopia. Int J Diabetes Dev Ctries 2019;39:749-55.

70 Animaw W, Seyoum Y. Increasing prevalence of diabetes mellitus in a developing country and its related factors. PLoS One 2017;12:e0187670.

71 Tesfaye Yunka T, Berhanu Mogas S, Zawdie B, et al. The hidden burden of diabetes mellitus in an urban community of Southwest Ethiopia. Diabetes Metab Syndr Obes 2020;13:2925-33.

72 Wolde HF, Derso T, Biks GA, et al. High hidden burden of diabetes mellitus among adults aged 18 years and above in urban Northwest Ethiopia. J Diabetes Res 2020;2020:9240398.

73 Gebreegziabiher G, Belachew T, Tamiru D. Abnormal glucose metabolism and associated risk factors among adults in Mekelle City, Ethiopia. Diabetes Metab Syndr Obes 2020;13:4017.

74 Darebo T, Mesfin A, Gebremedhin S. Prevalence and factors associated with overweight and obesity among adults in Hawassa City, southern Ethiopia: a community based cross-sectional study. BMC Obes 2019;6:8

75 Moges B, Amare B, Fantahun B, et al. High prevalence of overweight, obesity, and hypertension with increased risk to cardiovascular disorders among adults in Northwest Ethiopia: a cross sectional study. BMC Cardiovasc Disord 2014;14:155.

76 Abrha S, Shiferaw S, Ahmed KY. Overweight and obesity and its socio-demographic correlates among urban Ethiopian women: evidence from the 2011 EDHS. BMC Public Health 2016;16:636.

77 Bogale KA, Zewale TA. Determinant factors of overweight/obesity among federal ministry civil servants in Addis Ababa, Ethiopia: a call for sector-wise occupational health program. BMC Res Notes 2019;12:449 
78 Mekonnen T, Animaw W, Seyum Y. Overweight/obesity among adults in North-Western Ethiopia: a community-based cross sectional study. Arch Public Health 2018;76:18.

79 Dagne S, Gelaw YA, Abebe Z, et al. Factors associated with overweight and obesity among adults in northeast Ethiopia: a cross-sectional study. Diabetes Metab Syndr Obes 2019;12:391-9.

80 Janakiraman B, Abebe SM, Chala MB, et al. Epidemiology of general, central obesity and associated Cardio-Metabolic risks among university employees, Ethiopia: a cross-sectional study. Diabetes Metab Syndr Obes 2020;13:343.

81 Amare B, Moges B, Moges F, et al. Nutritional status and dietary intake of urban residents in Gondar, Northwest Ethiopia. BMC Public Health 2012;12:752.

82 Yeshaw Y, Kebede SA, Liyew AM, et al. Determinants of overweight/ obesity among reproductive age group women in Ethiopia: multilevel analysis of Ethiopian demographic and health survey. BMJ Open 2020;10:e034963.

83 Gebremariam LW, Chiang C, Yatsuya H, et al. Non-communicable disease risk factor profile among public employees in a regional City in northern Ethiopia. Sci Rep 2018;8:1-11.

84 Kassie AM, Abate BB, Kassaw MW. Education and prevalence of overweight and obesity among reproductive age group women in Ethiopia: analysis of the 2016 Ethiopian demographic and health survey data. BMC Public Health 2020;20:1-11.

85 Gutema BT, Chuka A, Kondale M, et al. The burden of malnutrition among adults residing in Arba Minch health and demographic surveillance site (HDSS): a who steps survey. J Nutr Metab 2020;2020:6986830.

86 Tesfaye TS, Zeleke TM, Alemu W, et al. Dietary diversity and physical activity as risk factors of abdominal obesity among adults in Dilla town, Ethiopia. PLoS One 2020;15:e0236671.

87 Yosef T, Bogale B, Destaw A, et al. The burden of overweight and obesity among long-distance truckers in Ethiopia. J Obes 2020;2020:4242789.

88 Hailemariam TW, Ethiopia SS, Alamdo AG, et al. Emerging nutritional problem of adult population: Overweight/Obesity and associated factors in Addis Ababa City communities, Ethiopia-A community-based cross-sectional study. J Obes 2020;2020:6928452

89 Molla MD, Wolde HF, Atnafu A. Magnitude of central obesity and its associated factors among adults in urban areas of northwest Ethiopia. Diabetes Metab Syndr Obes 2020;13:4169-78.

90 Solomon S, Mulugeta W. Disease burden and associated risk factors for metabolic syndrome among adults in Ethiopia. BMC Cardiovasc Disord 2019;19:236.

91 Abda E, Hamza L, Tessema F, et al. Metabolic syndrome and associated factors among outpatients of Jimma university teaching hospital. Diabetes Metab Syndr Obes 2016;9:47.

92 Workalemahu T, Gelaye B, Berhane Y, et al. Physical activity and metabolic syndrome among Ethiopian adults. Am J Hypertens 2013;26:535-40.

93 Tran A, Gelaye B, Girma B, et al. Prevalence of metabolic syndrome among working adults in Ethiopia. Int $\mathrm{J}$ Hypertens 2011;2011:193719.

94 Kerie S, Menberu M, Geneto M. Metabolic syndrome among residents of Mizan-Aman town, South West Ethiopia, 2017: a cross sectional study. PLoS One 2019;14:e0210969.

95 Gebreyes YF, Goshu DY, Geletew TK, et al. Prevalence of high bloodpressure, hyperglycemia, dyslipidemia, metabolic syndrome and their determinants in Ethiopia: evidences from the National NCDs STEPS survey, 2015. PLoS One 2018;13:e0194819.

96 Mengesha MM, Ayele BH, Beyene AS, et al. Clustering of elevated blood pressure, elevated blood glucose, and abdominal obesity among adults in dire Dawa: a community-based cross-sectional study. Diabetes Metab Syndr Obes 2020;13:2013-24.

97 Motuma A, Gobena T, Teji Roba K, et al. Metabolic syndrome among working adults in eastern Ethiopia. Diabetes Metab Syndr Obes 2020;13:4941-51.

98 Kibret KT, Mesfin YM. Prevalence of hypertension in Ethiopia: a systematic meta-analysis. Public Health Rev 2015;36:14.

99 Eikemo TA, Gkiouleka A, Rapp C, et al. Non-communicable diseases in Greece: inequality, gender and migration. Eur J Public Health 2018;28:38-47.

100 Serneels P. The nature of unemployment in urban Ethiopia, 2004.
101 Abera SF, Gebru AA, Biesalski HK, et al. Social determinants of adult mortality from non-communicable diseases in northern Ethiopia, 2009-2015: evidence from health and demographic surveillance site. PLoS One 2017;12:e0188968.

102 The World Bank. Ethiopian poverty assessment. Available: https:// www.worldbank.org/en/topic/poverty/publication/ethiopia-povertyassessment

103 Organization WH. Noncommunicable diseases country profiles 2018, 2018

104 Kaze AD, Schutte AE, Erqou S, et al. Prevalence of hypertension in older people in Africa: a systematic review and meta-analysis. J Hypertens 2017;35:1345-52.

105 Sarki AM, Nduka CU, Stranges S, et al. Prevalence of hypertension in low- and middle-income countries: a systematic review and meta-analysis. Medicine 2015;94:e1959.

106 Pampel F. Tobacco use in sub-Sahara Africa: estimates from the demographic health surveys. Soc Sci Med 2008;66:1772-83.

107 Francis JM, Grosskurth H, Changalucha J, et al. Systematic review and meta-analysis: prevalence of alcohol use among young people in eastern Africa. Trop Med Int Health 2014;19:476-88.

108 World Health Organization. Obesity and overweight. Available: https://www.who.int/news-room/fact-sheets/detail/obesity-andoverweight [Accessed 3 Mar 2020].

109 Neupane S, K.C. P, Doku DT. Overweight and obesity among women: analysis of demographic and health survey data from 32 sub-Saharan African countries. BMC Public Health 2015;16:30.

110 Sawaya AL, Martins PA, Grillo LP, et al. Long-term effects of early malnutrition on body weight regulation. Nutr Rev 2004;62:S127-33.

111 González-Barranco J, Ríos-Torres JM. Early malnutrition and metabolic abnormalities later in life. Nutr Rev 2004;62:S134-9.

112 Chivese T, Mahmoud W, Magodoro I, et al. Prevalence of type 2 diabetes mellitus in women of childbearing age in Africa during 2000-2016: protocol of a systematic review and meta-analysis. BMJ Open 2016;6:e012255

113 Mbanya JCN, Motala AA, Sobngwi E, et al. Diabetes in sub-Saharan Africa. Lancet 2010;375:2254-66.

114 Chen W, Li F, He C, et al. Elevated prevalence of abnormal glucose metabolism in patients with primary aldosteronism: a meta-analysis. Ir J Med Sci 2014;183:283-91.

115 Nguyen KA, Peer N, Mills EJ, et al. A meta-analysis of the metabolic syndrome prevalence in the global HIV-infected population. PLoS One 2016;11:e0150970.

116 Grover S, Nebhinani N, Padmavati R, et al. Metabolic syndrome in antipsychotic naïve patients with schizophrenia: pooled analysis of data from three Indian studies. Early Interv Psychiatry 2015;9:357-62

117 Hallajzadeh J, Safiri S, Mansournia MA, et al. Metabolic syndrome and its components among rheumatoid arthritis patients: a comprehensive updated systematic review and meta-analysis. PLoS One 2017;12:e0170361.

118 Mathers C, Stevens G, Mascarenhas M. Global health risks: mortality and burden of disease attributable to selected major risks. World Health Organization, 2009.

119 Kratz M, Baars T, Guyenet S. The relationship between high-fat dairy consumption and obesity, cardiovascular, and metabolic disease. Eur J Nutr 2013;52:1-24.

120 Auguste A, Dugas J, Menvielle G, et al. Social distribution of tobacco smoking, alcohol drinking and obesity in the French West Indies. BMC Public Health 2019;19:1424.

121 Gaskin C, Orellana L. Factors associated with physical activity and sedentary behavior in older adults from six low- and middle-income countries. Int J Environ Res Public Health 2018;15:908.

122 Njelekela MA, Mpembeni R, Muhihi A, et al. Gender-related differences in the prevalence of cardiovascular disease risk factors and their correlates in urban Tanzania. BMC Cardiovasc Disord 2009:9:30.

123 Menon J, Vijayakumar N, Joseph JK, et al. Below the poverty line and non-communicable diseases in Kerala: the epidemiology of non-communicable diseases in rural areas (ENDIRA) study. Int $J$ Cardiol 2015;187:519-24.

124 Casetta B, Videla AJ, Bardach A, et al. Association between cigarette smoking prevalence and income level: a systematic review and meta-analysis. Nicotine Tob Res 2017;19:1401-7. 